\title{
Smart Enhancement of UPFC Performance in Transmission Systems Using BPSO and ANNC
}

\author{
Rabab R. M. Eiada, Ebrahim A. Badran, and Ibrahim I. I. Mansy
}

\begin{abstract}
The power disturbances in the transmission system can be controlled and reduced by using unified power flow controller (UPFC). UPFC is used for controlling power flow in electrical transmission system. In this paper an algorithm for optimizing and smart controlling of UPFC, using an artificial neural network controller (ANNC) and a Binary Particle Swarm Optimization (BPSO), is proposed for smarting transmission system. The proposed algorithm controls the parameters of the UPFC. Therefore, a best performance of the UPFC is achieved and the transmission losses are minimized at different load conditions and variation of generation. Matlab is used for simulating the proposed algorithm and the test system. The results show that the UPFC using the proposed algorithm effectively act the proposed requirements.
\end{abstract}

Index Terms-UPFC, BPSO, ANNC, Reactive Power, Power Flow Control, Transmission line losses.

\section{INTRODUCTION}

Flexible AC transmission systems (FACTS) are the attractive alternatives for increasing the transmission capacity at high transmission levels. Due to the rapid growth in power electronics technology, FACTS devices are proposed recently for existing transmission facilities. Unified power flow controller (UPFC), as one of the FACTS devices, is considered to have the most powerful capability to control the power flow. Therefore, UPFC is used for increasing system performance. UPFC is able to control the power flow, mitigate the system oscillations, regulate the voltage, and enhance the transient stability $[1$, 2].

Mathematical modeling of UPFC is developed for determining the dynamic behavior of emerging solution for the power flow problems in the system [2,3]. For systems without power system stabilizers, power controller design is used to achieve effective damping. Different control methods are introduced for UPFC as conventional control, genetic algorithm (GA) [4], fuzzy logic (FL), and artificial neural network control (ANNC) methods [5].

In [6] a control variable is generated using ANNC to control the sending end voltage. In [7] an adaptive ANNC is used for damping of low frequency oscillations of UPFC.

Published on October 30, 2019.

Rabab R. M. Eiada, Faulty of Engineering, Mansoura University, Egypt.

(e-mail: r_reda7@yahoo.com )

Ebrahim A. Badran, Faulty of Engineering, Mansoura University, Egypt.

(email: ebadran@hotmail.com)

Ibrahim I. I. Mansy, Electrical Engineering Department, Mansoura University, Egypt.

(ebadran@mans.edu.eg)
Also, UPFC is used as an active power filter by applying ANNC in [8]. The real and reactive powers are modified using compensation controller of UPFC in [9]. In [10] the optimal location is reducing total power losses and consequently maximizing the net saving. According to the authors' survey, the previous researches not including are studies for two tasks; to determine the best optimal location and to achieve the best parameters of UPFC.

Therefore, in this paper, the UPFC optimal location is determined by Binary Particle Swarm Optimization (BPSO) to maintain the voltage of all buses within the designed limits during various conditions. Furthermore, ANNC is designed to control the UPFC parameters to inject the firing angles and generate the tuned pulses, for achieving the UPFC best performance. So, the transmission losses can be minimized.

\section{Control Structure of UPFC}

Fig. 1 illustrates the UPFC model. It contains two-voltage source converters, one in shunt and the other in series in the transmission line, and DC storage. This configuration facilitates active power flow between AC terminals. Each converter independently generates or absorbs reactive power at AC terminals [11]. The controllable injected voltage of series converter controls the voltage magnitude $\mathrm{V}$ and the angle $\delta+\theta$. Also, the reactive power is generated or absorbed by the shunt converter. The power flow through the controlled line depends on the adjustable voltage and adjustable VAr compensator [12].

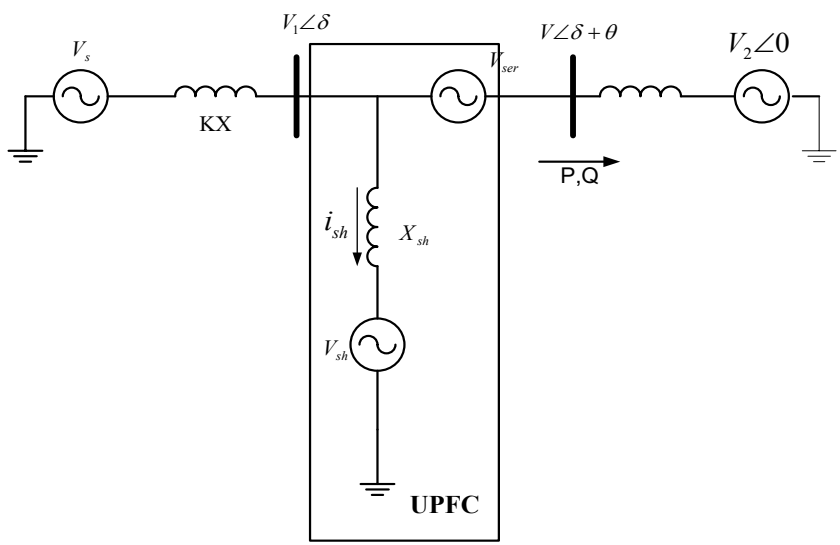

Fig. 1 Unified Power Flow Controller Model

The power flow depends on the voltage at the sending-end $\mathrm{V} 1 \angle \delta^{\circ}$, the line parameters $(\mathrm{KX})$, and voltage at the receiving- end $\mathrm{V} 2 \angle \mathrm{O}^{\circ}$. UPFC is considered the link between the sending voltage and receiving voltage buses of 
the UPFC. The sending bus is considered as a PQ bus in this study.

The limits of UPFC modeling are based on the power demands and transmission system topology [13]:

1. Maximum injected current by shunt inverter $\left(\mathrm{I}_{\mathrm{sh}}\right)$,

2. Maximum injected voltage by series inverter $\left(\mathrm{V}_{\mathrm{ser}}\right)$,

3. Maximum current in series inverter,

4. Maximum power transfer between inverters,

5. Line voltage limits of transmission line,

6. VA rating of UPFC inverters,

7. Line voltage at UPFC side, and

8. The system short circuit level.

Basically, UPFC controller is divided into internal and external controls. The internal control produces the series injected voltage by the two inverters and the desired shunt real and reactive currents $\left(\mathrm{I}_{\mathrm{sh}}\right)$ by controlling a proper output voltage. The external control is responsible for generating the voltage. The external control regulates the controlled system variables, as real and reactive powers $(\mathrm{P}, \mathrm{Q})$. The external control solves non-linear equations to get the reference voltages requested from internal control.

UPFC based on the PI controller is prone to severe dynamic interaction between active and reactive power flow [14]. In this paper, the PI internal controller is replaced by a proposed ANNC for improving the performance of UPFC by determining the best of UPFC parameters. The external control uses a proposed BPSO to determine the optimal location of UPFC.

\section{Modeling of The Proposed Algorithm}

The proposed algorithm model consist of UPFC detailed model and the proposed algorithm methodology.

\section{A. UPFC detailed model}

Fig. 2 shows the model of UPFC controller which consists of the shunt controller and the series controller. The

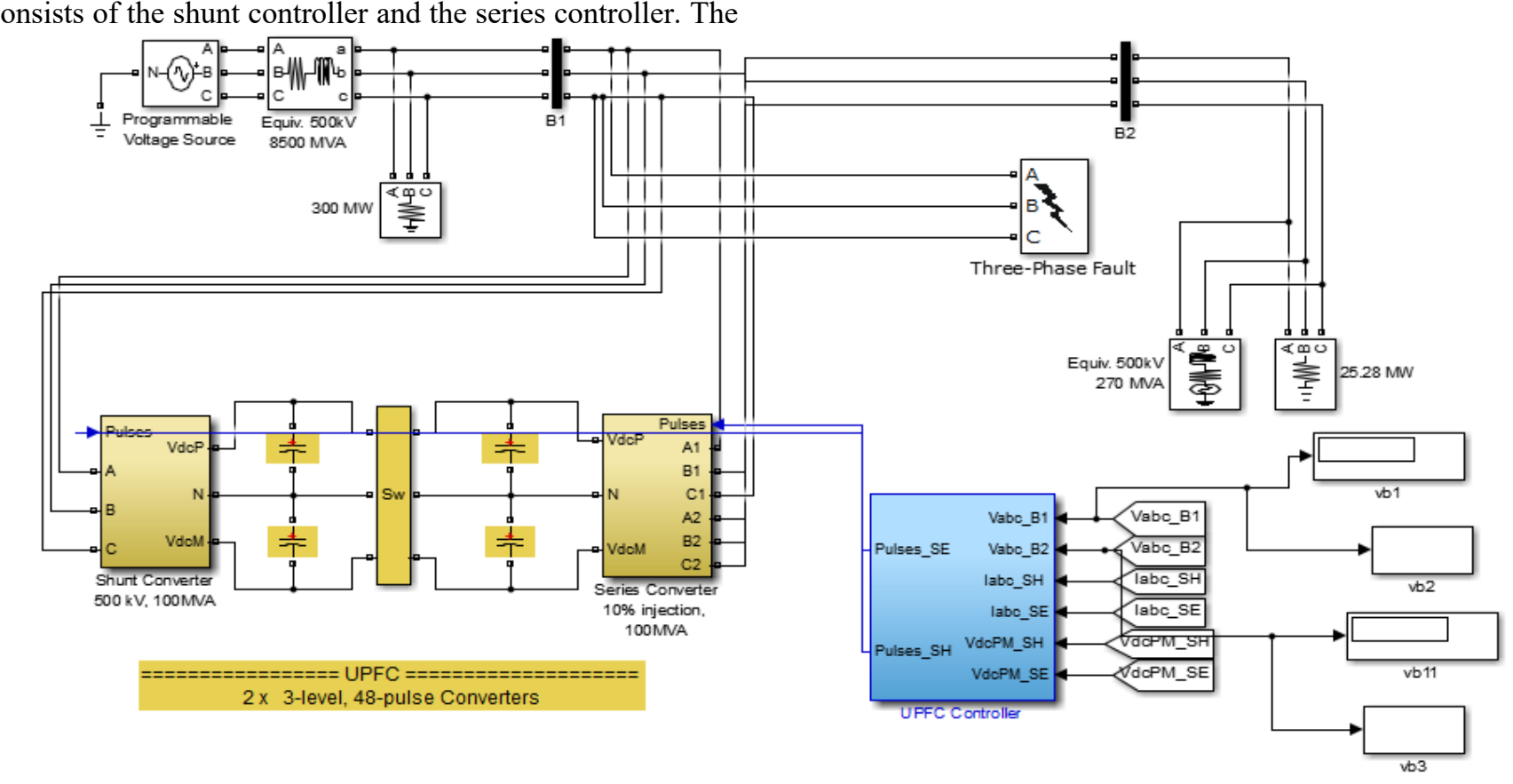

Fig. 2 . The UPFC controllers model using Matlab/Simulink
UPFC connects between B1 and B2 in the system. B1 is fed from the source and B2 feeds the load.

The inputs to the model are the three phase voltages of $\mathrm{B} 1$ and B2, the three phase currents of shunt and series, and the DC voltage. Also, the outputs of the model; the required injected voltage; (vb1, vb2, vb11, and vb3), can be determined from to controller. These values will be used in the proposed algorithm methodology as input data.

The injected power functions which are used in the proposed algorithm are listed in the following steps by equations (1) and (2). The injected power depends on the injected voltage and angle by shunt inverter:

$$
\begin{aligned}
P_{s h} & =\frac{V_{s h} V_{i}}{X_{s h}} \sin \left(\delta_{i}-\delta_{s h}\right) \\
Q_{s h} & =\frac{V_{i}^{2}}{X_{s h}}-\frac{V_{s h} V_{i}}{X_{s h}} \cos \left(\delta_{i}-\delta_{s h}\right)
\end{aligned}
$$

where:

$\mathrm{P}_{\text {sh }}$ : the injected active power by the shunt inverter

$\mathrm{Q}_{\text {sh }}$ : the injected reactive power by the shunt inverter

$\delta_{\mathrm{i}}$ : the phase shift angle at bus $\mathrm{i}$

$\delta_{\text {sh }}$ : the phase shift angle by the shunt inverter

$\mathrm{i}$ : The bus number

$\mathrm{X}_{\mathrm{sh}}$ : the reactance by the shunt inverter

$\mathrm{V}_{\text {sh }}$ : the injected voltage by the shunt inverter

$\mathrm{V}_{\mathrm{i}}$ : the injected voltage at bus $\mathrm{i}$

Fig. 3 shows that the voltages measurement; voltage at sending end (V1) and injected voltage of series converter $(\mathrm{V})$ and the reactive current $\left(\mathrm{I}_{\mathrm{sh}}\right)$ are the inputs to the PQ measurement system. It can be seen that the voltage and the current measurement elements convert the measurement values to direct component (d) and quadrature component (q). according to equations (3) and (4):

$$
\begin{aligned}
& \mathrm{P}=\mathrm{Vd} * \mathrm{Id}+\mathrm{Vq}^{*} \mathrm{Iq} \\
& \mathrm{Q}=\mathrm{Vq} \mathrm{q}^{*} \mathrm{Id}-\mathrm{Vd}^{*} \mathrm{Iq}
\end{aligned}
$$


The PQ measurement block computes active power $(\mathrm{P})$ and reactive power $(\mathrm{Q})$ based on the values of direct

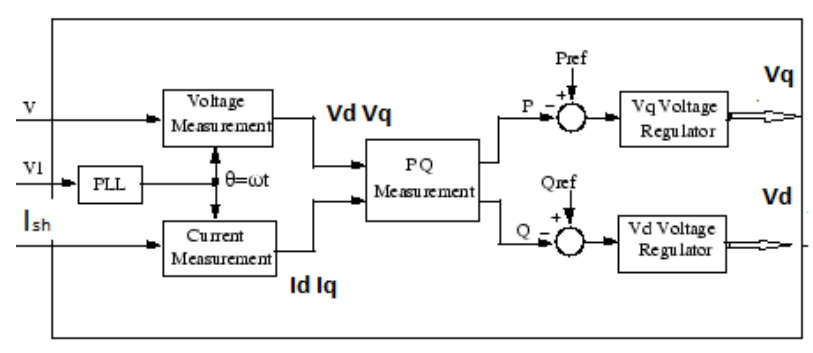

Fig. 3 The voltage and current measurement

Fig. 4 shows the calculations of $\mathrm{Vd}$ and $\mathrm{Vq}$ for series converter. This depends on the measurement system where injected voltage of series converter in direct component $\mathrm{Vd}$, injected voltage of series converter in quadrature component $\mathrm{Vq}$, reactive power $\mathrm{Q}$, and active power $\mathrm{P}$ are calculated. This are derived from reactive reference (Qref), active power reference (Pref), frequency (f), and three phase voltage line at sending end $(\mathrm{V} 1 \mathrm{abc})$. Therefore, the required firing angle are generated of the series converter.

Fig. 5 shows the calculations of required current such as the reactive current reference (Iqref), reactive current (Iq) in quadrature components for shunt converter. This depends on the measurement system where Iq, Iqref, $\mathrm{P}$, and, $\mathrm{Q}$ are calculated. This are determined from PQ computation of Qref, Pref, $\mathrm{P}$, and Vabc. Therefore, the required firing angle is generated of the shunt converter.

These components are used as input for the program of the proposed algorithm after the training stage. The training procedure of ANN for the pulses of both series and shunt converters. Therefore, the injected voltage in series converter and the required injected reactive current in shunt converter can be determined.

\section{B. The proposed algorithm methodology}

The most useful applications for smart operation of the transmission system are fast wide area control [15]. Therefore, fast controllers are needed. Because of their expense, the number and type of FACTS must be carefully selected, but this would be easier to do once the controller optimizes the overload in transmission lines and plan the reactive power to adjust the bus voltage [16]. In this paper, a proposed algorithm is introduced for optimizing and smart controlling of UPFC, using BPSO and ANNC, is proposed for smarting transmission system. The proposed algorithm locates the optimal location and controls the parameters of the UPFC. Therefore, a best performance of the UPFC is achieved and the transmission losses are minimized at different load conditions and variation of generation.

Fig. 6 shows the flow chart of the proposed algorithm. It consists of four sub-programs; the first subprogram calculates the power flow for steady state condition with UPFC. The output of this sub-program is used to the input data for next sub-program. The active power flow, reactive power flow, and voltage on all buses are determined.

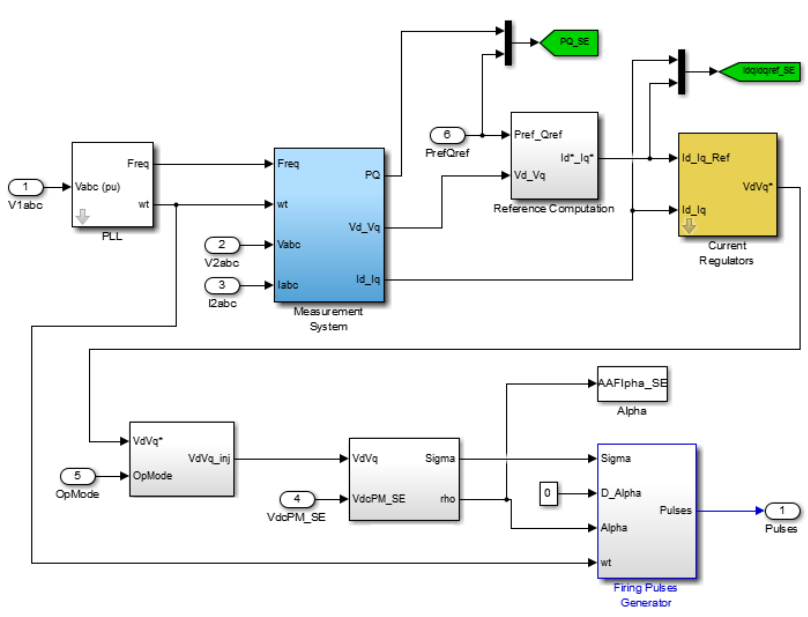

Fig. 4 Firing angle generator Model using Matlab /simulation of series converter

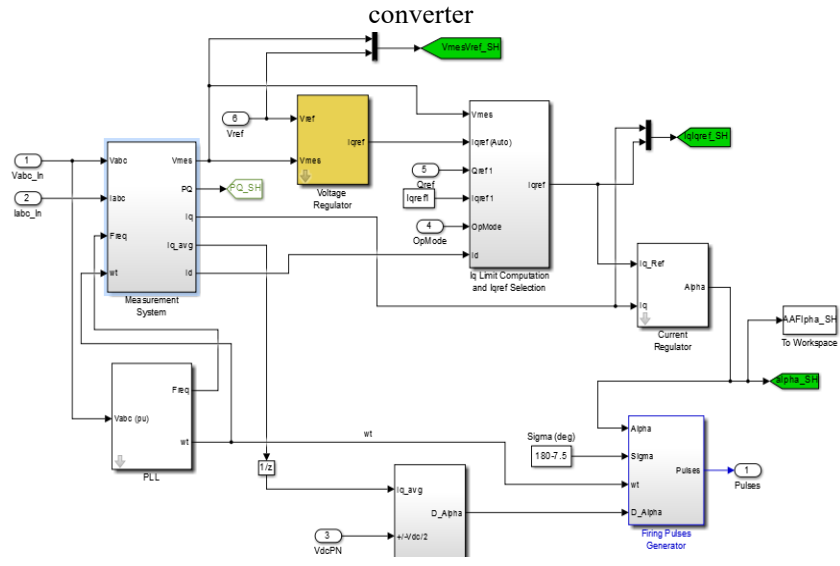

Fig. 5 firing angle generator Model using Matlab/simulation of shunt converter

The second sub-program calculates the desired active power (Ppdes), the desired reactive power (Qqdes ), and the desired voltage (Vss) in steady state condition. The constrains of UPFC; such as series voltage $\left(\mathrm{V}_{\text {ser }}\right)$ within range of $\left[\begin{array}{ll}0.02 & 0.2\end{array}\right]$ and shunt voltage $\left(\mathrm{V}_{\mathrm{sh}}\right)$ within range of [0.9 1.1], are used.

The objective function is given in equation (5). The equality constrains are given in equation (6), and the inequality constrains of active power, reactive power and voltage are given in equation (7). Also, the constrains of maximum power flow in transmissions lines is given in equation (8).

$$
\begin{aligned}
& \boldsymbol{f}=\sum\{a 1(V s s-V s)+a 2(P p-P p d e s)+a 3(Q q- \\
& \text { Qqdes })\} \\
& \mathrm{P}_{\mathrm{Gi}}-\mathrm{P}_{\mathrm{Di}}=\mathrm{P}_{\mathrm{i}}, \quad \mathrm{Q}_{\mathrm{Gi}}-\mathrm{Q}_{\mathrm{Di}}=\mathrm{Q}_{\mathrm{i}} \\
& V_{\text {imin }} \leq V_{i} \leq V_{\text {imax }}, \quad Q_{\text {imin }} \leq Q_{i} \leq Q_{\text {imax }} \\
& P_{i j} \leq P_{i j}^{\max }
\end{aligned}
$$

where:

$\mathrm{P}_{\mathrm{Gi}}$ : the active power of the generation at bus $\mathrm{i}$

$P_{D i}$ : the active power of the load at bus $i$

$\mathrm{P}_{\mathrm{i}}$ : the injected active power at bus $\mathrm{i}$

$\mathrm{Q}_{\mathrm{Gi}}$ : the reactive power of the generation at bus $\mathrm{i}$

QDi : the reactive power of the load at bus $i$

$\mathrm{Q}_{\mathrm{i}}$ : the injected reactive power at bus $\mathrm{i}$

$\mathrm{V}_{\text {imin, }} \mathrm{V}_{\text {imax }}$ : the minimum and maximum values of voltage at bus $i, V_{i}$ : the voltage at bus $i$

Qimin, Qimax: the minimum and maximum values of reactive power〉 
$\mathrm{P}_{\mathrm{ij}}$ : the active power flow in the line (i-j).

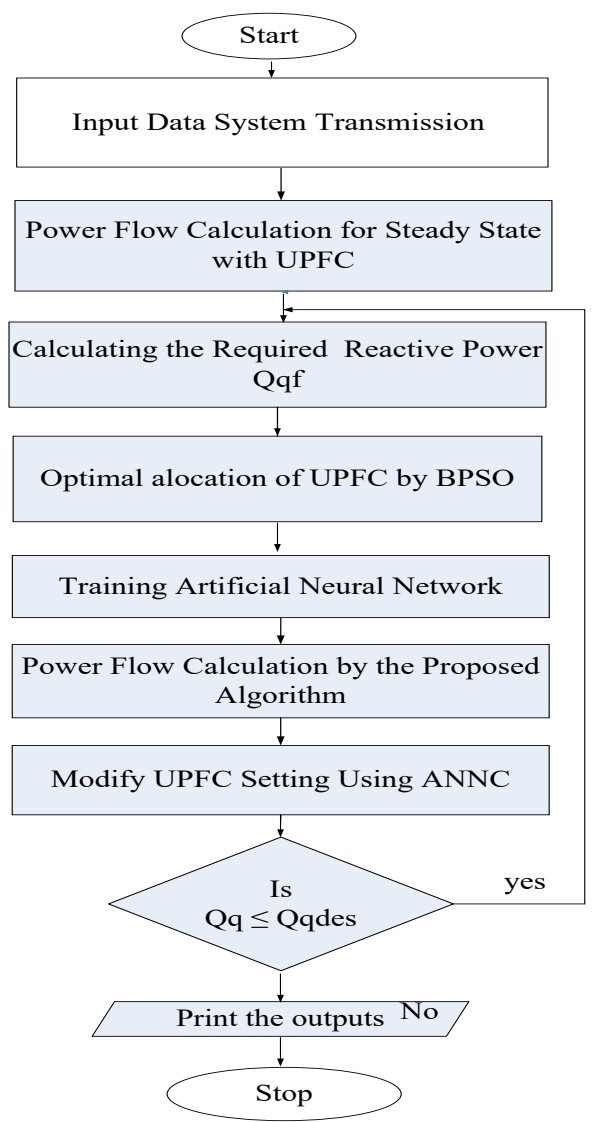

Fig. 6 The flow chart of the proposed algorithm methodology

The proposed algorithm is implemented to optimize the power flow, to minimize overload transmission lines, to plan reactive power, and to adjust the voltage of buses by using BPSO.

It does not only optimize the required reactive power at the two buses which UPFC is to be connected between according to their voltages, but also according to the buses which are not connected to it.

Then, the injected/absorbed reactive powers for the controlled buses are determined. The amount of voltage and angle to be injected and the optimal location for UPFC in the system are identified by using BPSO [17] and the minimization of total power losses in transmission line is achieved.

In the third sub-program, the required active power and reactive power according to the optimized voltage and controlled buses are determined. It can be seen that in this part the UPFC can be selected to operate as single unit; STATCOM or SSSC or to operate as a double controller.

In the fourth sub-program, ANNC determines the best parameters of UPFC depending on the optimal location of UPFC that determined by BPSO, which are calculated in the previous sub-programs. Furthermore, the minimization of the total power losses in proposed in this sub-program.

Fig. 7 shows the proposed ANNC layers which consist of two input layers; the active power Pp and the reactive power Qq, two output layers; the firing angle generator of series converter $\left(\alpha_{s}\right)$ and the firing angle generator of shunt converter $\left(\alpha_{\mathrm{sh}}\right)$, and twenty hidden layers. The proposed
ANNC is trained based on the training dataset given from the power flow with UPFC. Here, $\alpha_{\mathrm{s}}$ and $\alpha_{\mathrm{sh}}$ are the output to the network are depending on the input (Pp, Qq).

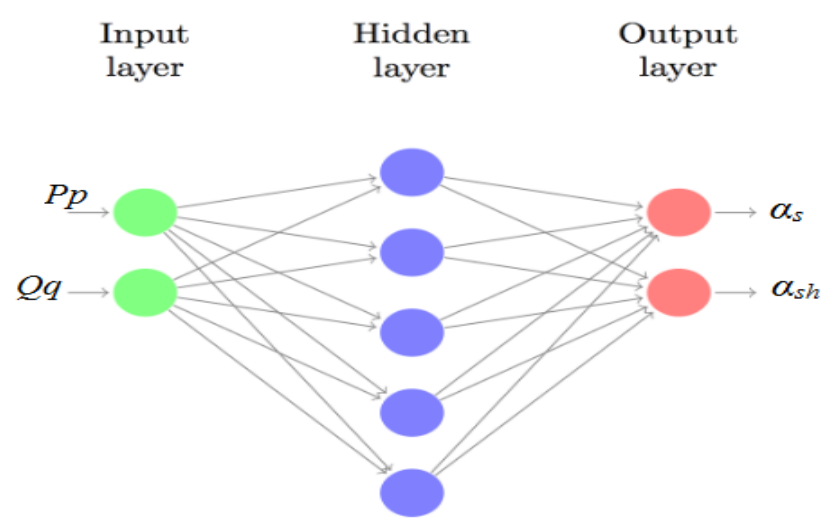

Fig. 7 Three-layer for the proposed ANNC

\section{Results AND Discussion}

Fig. 8 illustrates the 14-Bus IEEE test system [18]. The voltage of the generating buses is $230 \mathrm{kV}$, for transmission purpose, with a base of 100 MVA. UPFC is given between the buses B5 and B2.

Shunt and series converters of UPFC are exchanging power through a DC bus. The series converter can inject a maximum $10 \%$ of nominal line-to-ground voltage in series with this line. The shunt converter is connected at B2 and series converter is between $\mathrm{B} 5$ and $\mathrm{B} 2$.

MATLAB is used to implement the proposed algorithm on the 14-Bus IEEE test system. BPSO is used to determine optimal values of local best (pbest) and global best (gbest), active and reactive powers at steady state condition (Ppdes, Qqdes) and active and reactive powers at abnormal states condition (Pp, Qq), series voltages in steady and abnormal states (Vssk, Vssf), and shunt voltages in steady and abnormal states (Vsk, Vsf).

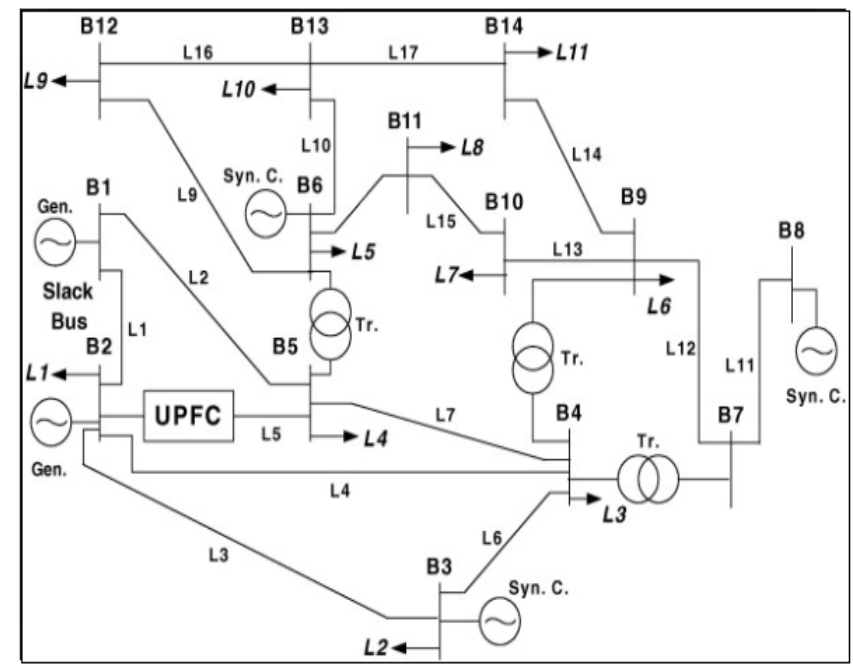

Fig. 8 the 14-Bus IEEE Test System.

Fig. 9a shows the voltage of buses with load variations when B2 generation is $120 \mathrm{MW}$ and 45 Mvar. The load variation values at $\mathrm{B} 3$ are $100 \%, 110 \%$, and $120 \%$ of the full load. It can be seen that the proposed algorithm improves 
the voltage at all buses to keep the voltage within acceptable limits from $0.9 \mathrm{pu}$ to $1.1 \mathrm{pu}$.

Fig. $9 \mathrm{~b}$ shows the voltage of buses with load variations when B2 generation is $100 \mathrm{MW}$ and 35 Mvar. The load variation values at B3 are $100 \%, 110 \%$, and $120 \%$ of the full load. It can be seen that the proposed algorithm improves the voltage at all buses to keep the voltage within acceptable limits from $0.9 \mathrm{pu}$ to $1.1 \mathrm{pu}$.

Fig. 9c shows the voltage of buses with load variations when B2 generation is $30 \mathrm{MW}$ and $15 \mathrm{Mvar}$. The load variation values at B3 are $100 \%, 110 \%$, and $120 \%$ of the full load. It can be seen that the proposed algorithm improves the voltage at all buses to keep the voltage within acceptable limits from $0.9 \mathrm{pu}$ to $1.1 \mathrm{pu}$. Also, a different condition is used with upper voltage constrain of $1.05 \mathrm{pu}$ as given in the Fig. 9d. It is noted that the proposed algorithm success in adjusting within the new limits.

Fig. 10a shows the active power variation with load variations when B2 generation is $120 \mathrm{MW}$ and 45 Mvar. The load variation values at B3 are $100 \%, 110 \%$, and $120 \%$ of the full load. Fig. 10b shows the active power variation with load variations when B2 generation is $100 \mathrm{MW}$ and 35 Mvar. The load variation values at B3 are $100 \%, 110 \%$, and $120 \%$ of the full load. Fig. 10c shows the active power variation with load variations when $\mathrm{B} 2$ generation is $30 \mathrm{MW}$ and 15 Mvar. The load variation values at B3 are $100 \%$, $110 \%$, and $120 \%$ of the full load. It can be seen that the active power values at all buses are determining within constrains by using the proposed BPSO and ANNC -based algorithm of UPFC.

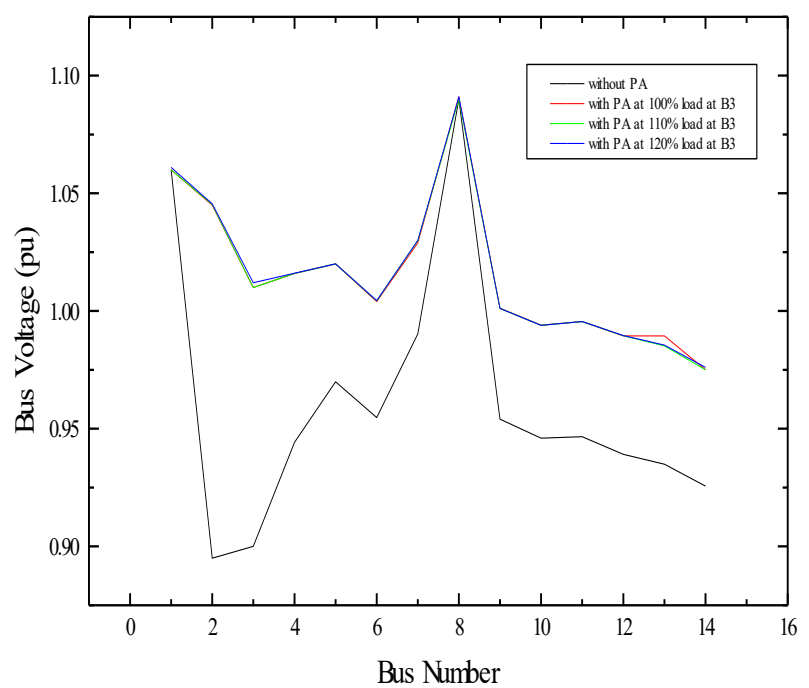

a) at generation of $120 \mathrm{MW} \& 45 \mathrm{Mvar}$

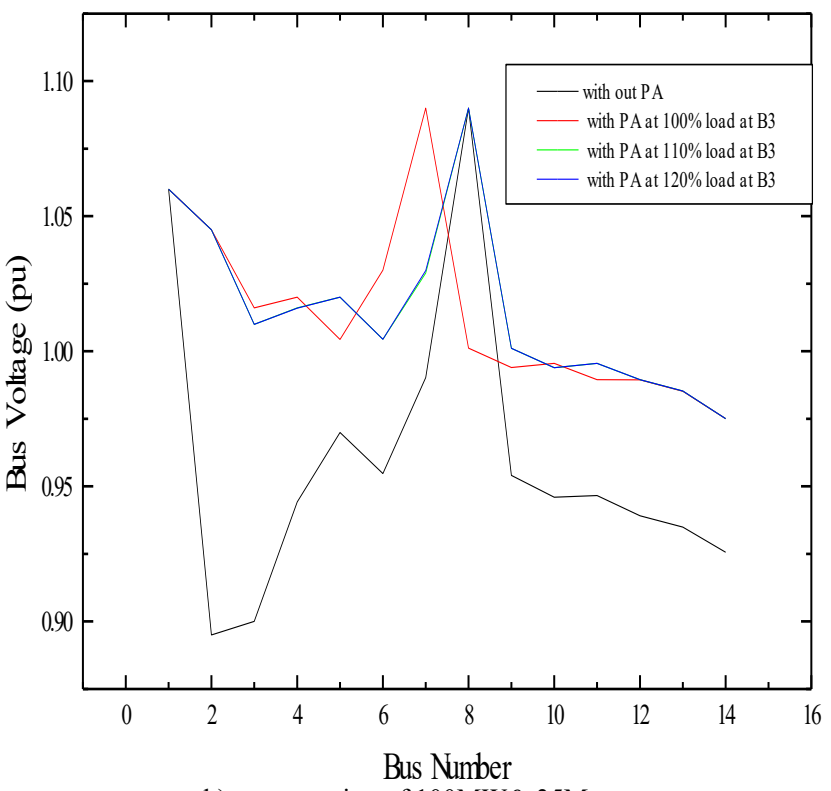

b) at generation of $100 \mathrm{MW} \& 35 \mathrm{Mvar}$

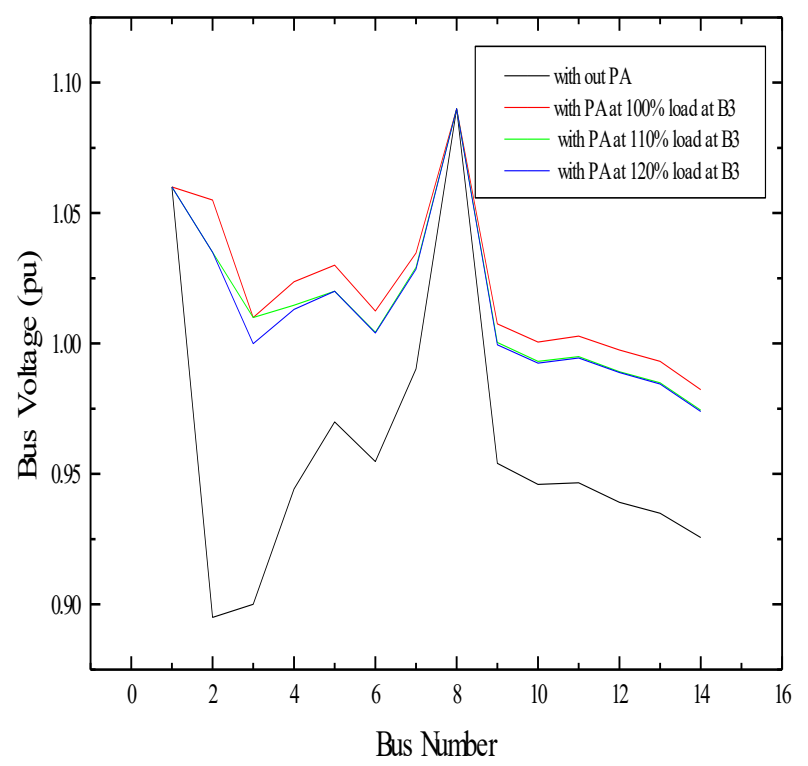

c) at generation of $30 \mathrm{MW} \& 15 \mathrm{Mvar}$

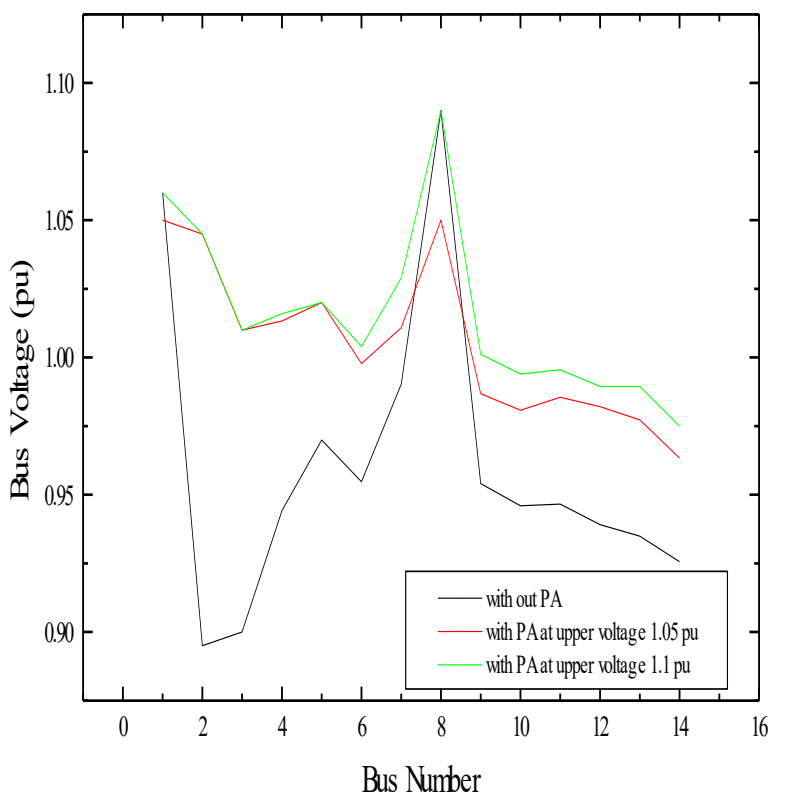

d) at generation of $120 \mathrm{MW} \& 45 \mathrm{Mvar}$ with upper votageconstrains $1.05 \mathrm{pu}$ Fig. 9 Voltages due to different loads at B3 and different generation at B2 


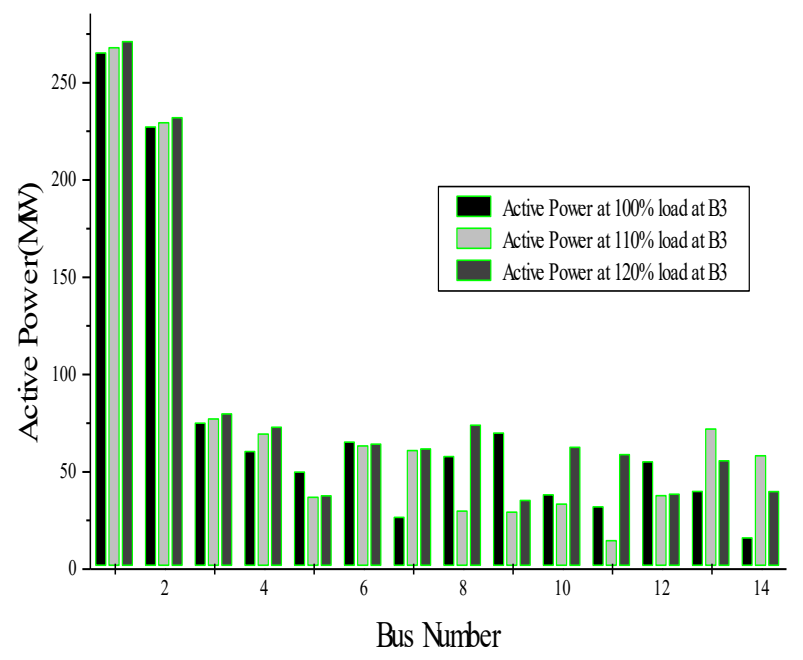

a) at generation of $120 \mathrm{MW} \& 45 \mathrm{Mvar}$

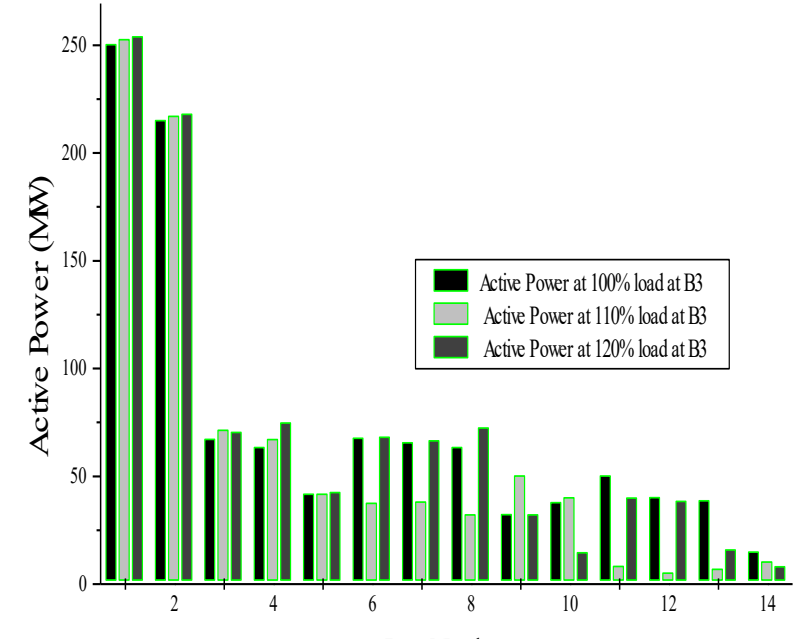

Bus Number

b) at generation of $100 \mathrm{MW} \& 35 \mathrm{Mvar}$

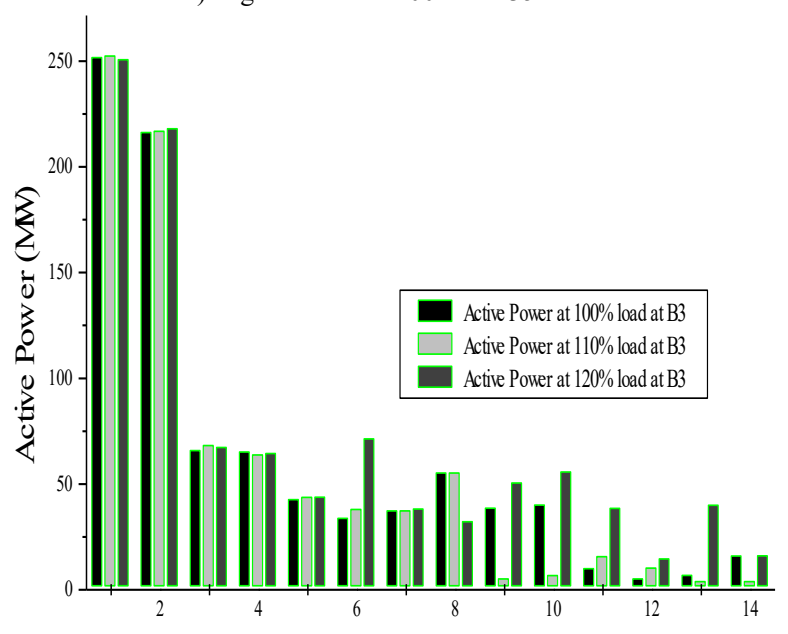

Bus Number

c) at generation of $30 \mathrm{MW} \& 15 \mathrm{Mvar}$

Fig. 10 Active power due to different loads at B3 and different generation at B2

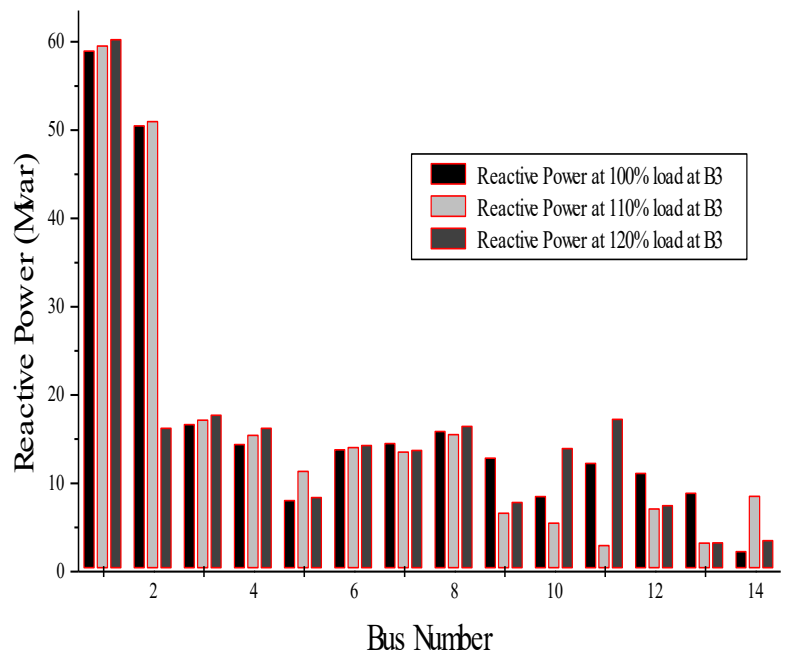

a) at generation of $120 \mathrm{MW} \& 45 \mathrm{Mvar}$

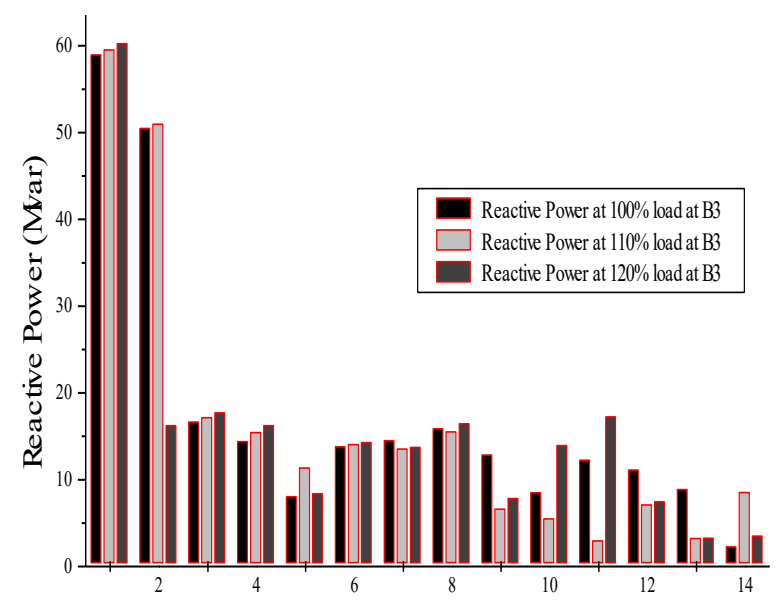

Bus Number

b) at generation of 100MW\&35Mvar

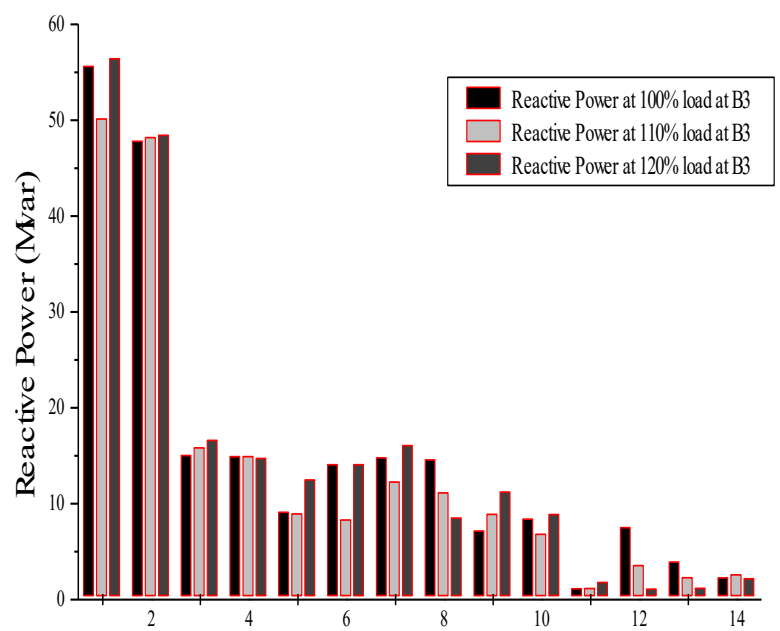

Bus Number

c) at generation of $30 \mathrm{MW} \& 15 \mathrm{Mvar}$

Fig. 11 Reactive power due to different loads at B3 and different generation at B2

Fig. 11a shows the reactive power variation with load variations when B2 generation is $120 \mathrm{MW}$ and $45 \mathrm{Mvar}$. The load variation values at B3 are $100 \%, 110 \%$, and $120 \%$ of the full load. Also, Fig. $11 \mathrm{~b}$ shows the reactive power variation with load variations when B2 generation is 100 MW and 35 Mvar. The load variation values at B3 are $100 \%, 110 \%$, and $120 \%$ of the full load. Furthermore, Fig. $11 \mathrm{c}$ shows the reactive power variation with load variations 
when B2 generation is $30 \mathrm{MW}$ and 15 Mvar. The load variation values at B3 are $100 \%, 110 \%$, and $120 \%$ of the full load. It can be seen that the reactive power values at all buses are determining within constrains by using the proposed BPSO and ANNC -based algorithm of UPFC. The proposed algorithm enhances the active power flow and the reactive power flow.

Fig. 12a gives the total power losses during various load conditions without and with using the proposed BPSO and ANNC-based algorithm of UPFC. It can be seen that the proposed algorithm reduces the total power losses from $0.083 \mathrm{pu}$ to $0.082 \mathrm{pu}$ at full load, with the generator at B2 of $120 \mathrm{MW}$ and 45Mvar, from $0.084 \mathrm{pu}$ to $0.083 \mathrm{pu}$ at generator of $100 \mathrm{MW}$ and $35 \mathrm{Mvar}$ and from $0.089 \mathrm{pu}$ to $0.087 \mathrm{pu}$ at generator of $30 \mathrm{MW}$ and $15 \mathrm{Mvar}$.

Furthermore, when the load is increased, Fig. 12b gives the total power losses without and with using the proposed BPSO and ANNC -based algorithm of UPFC. It can be seen that the proposed algorithm reduces the total power losses from $0.086 \mathrm{pu}$ to $0.084 \mathrm{pu}$ at $110 \%$ loading, with the generator at B2 of $120 \mathrm{MW}$ and $45 \mathrm{Mvar}$, from $0.088 \mathrm{pu}$ to $0.085 \mathrm{pu}$ at generator of $100 \mathrm{MW}$ and $35 \mathrm{Mvar}$, and from 0.092 pu to $0.090 \mathrm{pu}$ at generator of $30 \mathrm{MW}$ and $15 \mathrm{Mvar}$.

Fig. 12c gives the total power losses without and with using the proposed BPSO and ANNC -based algorithm of UPFC. It can be seen that the proposed algorithm reduces the total power losses from $0.089 \mathrm{pu}$ to $0.086 \mathrm{pu}$ at $120 \%$ loading, with the generator at B2 of $120 \mathrm{MW}$ and 45 Mvar, from $0.09 \mathrm{pu}$ to $0.087 \mathrm{pu}$ at generator of $100 \mathrm{MW}$ and 35 Mvar, and from $0.095 \mathrm{pu}$ to $0.092 \mathrm{pu}$ at generator of $30 \mathrm{MW}$ and 15 Mvar.

Depend on the simulation results, the proposed algorithm acts to give the better performance for system response to different values of load and different values of generator; the voltage is improved and the total losses are reduced.

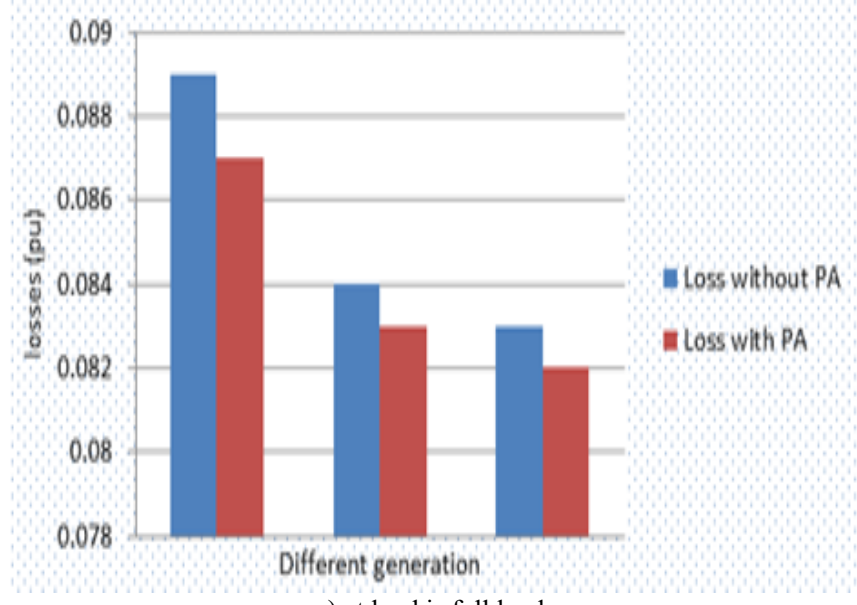

a) at load is full load

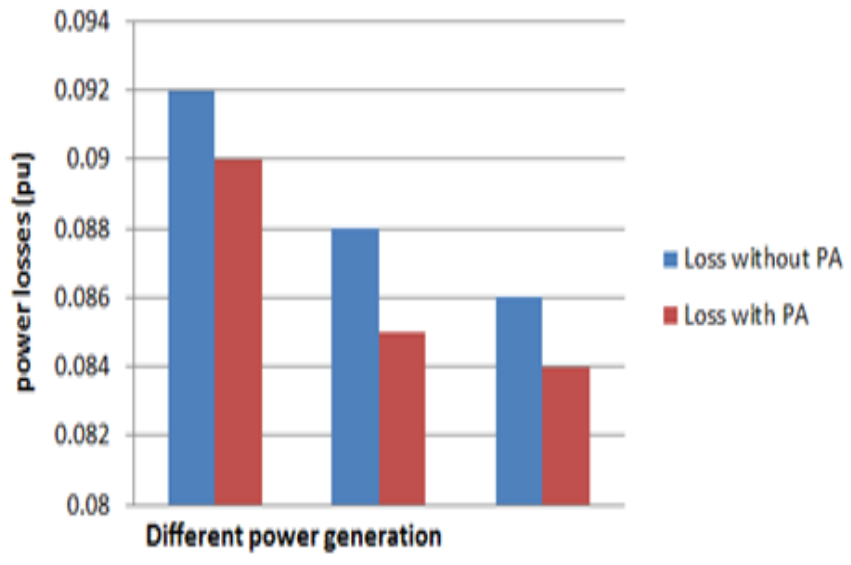

b) at load is $110 \%$ loading

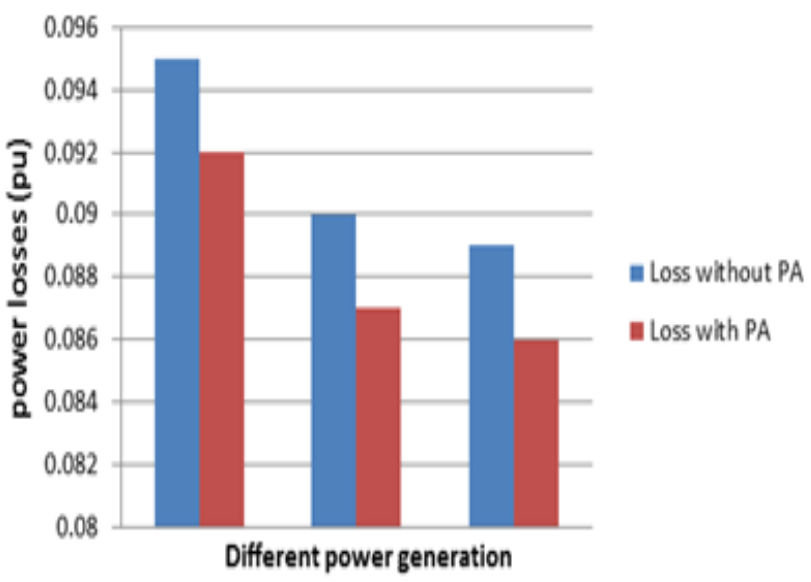

c) at load is $120 \%$ loading

Fig. 12 Total Power Losses due to different generation at B2 and different load at B3

\section{Conclusions}

A proposed algorithm of UPFC for smart transmission system is introduced in this paper. The introduced algorithm is based on BPSO and ANNC. The optimal location of the UPFC device is determined using BPSO and the best parameters for the selected UPFC device, is calculated using ANNC.

The proposed algorithm is designed, trained, and tested to achieve the optimal solution. The IEEE14-bus test system model in Matlab/Simulink is used for verification of proposed algorithm. The proposed algorithm acts two required tasks; firstly, adjusting the voltage at the system buses within the acceptable limits, and secondly, minimizing the total losses in the transmission lines. The proposed algorithm successes at different values of loads and different values of generation. Therefore, it is concluded that the proposed algorithm can be used for smarting transmission system. The results show that the proposed algorithm successes to effectively do the required tasks.

\section{REFERENCES}

[1] P. Mohanavel and T. A. Ragha Vendiran, "Artificial Intelligence Based Adaptive Power Oscillation Damping Controller for Power System Equipped with UPFC", International Journal of Research in Engineering \& Advanced Technology (IJREAT), Vol. 1, No. 4, August-September, 2013.

[2] K. Krishnaveni and G. T. R. Das, "ANN Based Control Patterns Estimator for UPFC Used in Power Flow Problem", Journal of Theoretical and Applied Information Technology, 2007. 
[3] Y. Yuan, X. Kong, J. Liu, and Y.Wang," Harmonic Influence Analysis of Unified Power Flow Controller based on Modular Multilevel Converter", Journal of Modern Power Systems and Clean Energy (MPCE), January, 2016.

[4] C. Ersavas, and E. Karatepe, "Optimal Allocation of FACTS Devices Under load uncertainty Based on Penalty Functions with genatic algorithm", Electrical Engineering (ELEN), Springer, Vol. 99, 2017, pp. 73-84.

[5] Sh. Ahmad, F. M. Albatsh, S. Mekhilef and H. Mokhlis, "Fuzzy based Controller for Dynamic Unified Power Flow Controller to Enhance Power Transfer Capability", Energy Conversion and Management, Vol. 79, 2014, pp. 652-665.

[6] A. Mohanty and M. Viswavandya, "A Novel ANN Based UPFC for Voltage Stability and Reactive Power Management in a Remote Hybrid System", International Conference on Intelligent Computing, Communication \& Convergence, Procardia Computer Science, 2015, pp. $555-560$.

[7] D. Ramesh and L. V. M. Babu, "A UPFC Damping Control Scheme Using Lead-Lag and ANN Based Adaptive Controllers", International Journal Computer Technology \& Applications, Vol. 3, No. 5, September-October 2012, pp.1677-1681.

[8] M. Sh. Soruban, J. D. Sathyaraj, and J. G. Chandran, "Power Quality Enhancement Using UPFC as an Active Power Filter for Renewable Power Generation", International Journal of Advanced Research in Electrical, Electronics and Instrumentation Engineering, Vol. 4, No. 3, March 2015.

[9] S. Pasha and G. R. Das, "Analysis of UPFC Using ANN Controller for Real and Reactive Power Coordination", International Journal of Electrical and Electronics Engineering Research, Vol. 5, No. 2, April 2015, pp. 73-84.

[10] E. S. Ali, S. M. Abd Elazim, and A. Y. Abdelaziz, "Optimal Allocation and Sizing of Renewable Distributed Generation Using Ant Lion Optimization Algorithm", Electrical Engineering (ELEN), Springer, Vol. 100, 2018, pp. 99-109.

[11] B. Gopinath, S. Kumar and S. J. Michael, "Unified Power Flow Controller (UPFC) for Dynamic Stability in Power System using Modern Control Techniques", International Journal of Engineering and Advanced Technology, Vol. 2, No. 4, April 2013.

[12] M. E. C. Brito, M. C. Cavalcanti, L. R. Limongi, F. A. S. Neves, and G. M. S. Azevedo, "Adjustable VAr Copmensator with Losses Reduction in the Electric System", Electrical Engineering (ELEN), Springer, Vol. 100, 2018, pp. 2165-2175.

[13] S. K. Gupta, M. Singh and H. D. Sharma, "Installation of UPFC for enhancing overall performance of electrical power system", Russian Electrical Engineering, May 2017, Volume 88, Issue 5, pp 314-320.

[14] G. V. Prasad, S. M. Ali, and M. P. Lalitha, "Power Quality Improvement Using ANN Logic Based UPQC for Harmonic Distortion", International Journal of Industrial Electronics and Electrical Engineering, Vol. 2, No. 1, Janune 2014.

[15] O. Thomas and W. James, "Smart Grid Wide-Area Transmission System Visualization", Elsevier B.V. or its licensors or contributors. ScienceDirect, Vol. 1, Issue 4, December 2015, pp. 466-474.

[16] S. Kahourzade, A. Mahmoudi and H. Bin-Mokhlis, "A Comparative Study of Multi-Objective Optimal Power Flow Based on Particle Swarm, Evolutionary Programming, and Genetic Algorithm", Journal of Electrical Engineering, Vol. 97, 2015, pp. 1-12.

[17] R. R. M. Eiada, E. A. Badran, and I. I. I. Mansy, "A Proposed BPSOBased Algorithm for UPFC in Smart Transmission System", 17th International Middle East Power Systems Conference (MEPCON 2015), Mansoura, Egypt, Decemper 2015. [18] A. R. Bhowmik and C. Nandi, "Implementation of Unified Power Flow Controller (UPFC) for Power Quality Improvement in IEEE 14-Bus System", International Journal Computer, Technology, Vol. 2, No. 6, 1996, pp. $1889-1896$. 